\title{
Analisis Faktor-Faktor Penyebab Terjadinya Selisih Jumlah Stok Suku Cadang Di Gudang Bengkel Perawatan Alat Berat PT. "X"
}

\author{
Syahruddin \\ Jurusan Teknik Mesin Alat Berat \\ Jl. Soekarno-Hatta Km.8 Balikpapan Telp. (0542)860895, 862305, Fax.861107 \\ E-mail:Syahruddin@poltekba.ac.id
}

\begin{abstract}
This study aims to determine the factors that cause the difference in the number of recorded stock of spare parts available in the warehouse with PT. " $X$ " and the issues at the warehouse PT. " $X$ " as well as the efforts that need to be done to overcome these problems. Field research by the method of observation, documentation and interview with the supervisor, foreman and employees / warehouse staff committed to the process of receiving, stock in, invetory, stock out and stock opname. The data collected are quantitative data includes data spare parts and spare parts as well as the difference and qualitative data covering warehouse management condition and the cause of the problems that occurred in the warehouse. Research results are the factors that cause the difference in the number of recorded stock of spare parts available in the warehouse with PT. "X" is the item moved to the new warehouse 198 items (23\%), spending without FPB 46 items (5\%), One of the cutting stock 42 item (5\%), do pengadjustan 442 items (52\%) and the results of adjustment auditing 119 items (14\%). Problems on the warehouse PT. " $X$ " and the efforts made to overcome that: when the officer is not rigorous checking process parts using sampling methods in checking the spare parts, the repair effort is to check the spare parts entered with 100\% inspection methods. Spare parts storage activities are carried out is still not good, then the repair effort is put parts or goods appropriately and neatly with the FIFO principle. Lack of spare parts that can come out without the FPB and cuts the number of parts, the repair effort is to store spare parts on each shelf and manufacture of card stock to control the goods out. Control tasks are not carried out properly, then the repair effort is tracking the items spare parts there is difference for re recorded existence.
\end{abstract}

Key Words: Sparepart, warehouse, inventory, heavy equipment maintenance and FIFO principle

\begin{abstract}
Abstrak
Penelitian ini bertujuan untuk mengetahuifaktor-faktor penyebab terjadinya selisih jumlah stok suku cadang yang terdata dengan yang tersedia di gudang $P T$. "X"dan permasalahan-permasalahan pada gudang $P T$. " $X$ " serta usaha-usaha yang perlu dilakukan untuk mengatasi permasalahan tersebut.Penelitian lapangan dengan metode observasi, dokumentasi dan wawancara kepada supervisor, foreman dan karyawan/staff gudang yang dilakukan pada proses penerimaan, penyimpanan, peneluaran dan pengontrolan. Data yang dikumpulkan adalah data kuantitatif yang meliputi data suku cadang dan selisih suku cadang serta data kualitatif yang meliputi kondisi pengelolaan gudang dan penyebab dari kendala yang terjadi pada gudang tersebut. Hasil penelitiannya adalah faktor-faktor penyebab terjadinya selisih jumlah stok suku cadang yang terdata dengan yang tersedia di gudang PT. " $X$ " adalah barang pindah ke gudang baru 198 item (23\%), pengeluaran tanpa FPB 46 item (5\%), Salah pemotongan stok 42 item (5\%), dilakukan pengadjustan 442 item (52\%) dan hasil adjustment audit 119 item (14\%). Permasalahan pada gudang PT. " $X$ " dan usaha yang dilakukan untuk mengatasinya yaitu: Petugas tidak teliti saat proses pengecekan suku cadang menggunakan metode sampling dalam pengecekan suku cadang, maka usaha perbaikannya adalah melakukan pengecekan suku cadang masuk dengan metode 100\% inspection. Kegiatan penyimpanan suku cadang yang dilaksanakan masih kurang baik, maka usaha perbaikannya adalah menempatkan suku cadang atau barang secara tepat dan rapi dengan prinsip FIFO. Adanya suku cadang yang dapat keluar tanpa adanya FPB dan pemotongan jumlah suku cadang, maka usaha perbaikannya adalah dengan menyimpan suku cadang pada masing-masing rak dan pembuatan stock card untuk mengontrol barang keluar. Aktivitas pengontrolan tidak dilaksanakan dengan baik, maka usaha perbaikannya adalah melakukan tracking pada item suku cadang yang terjadi selisih untuk didata ulang keberadaannya.
\end{abstract}

Kata Kunci: Suku cadang, gudang, inventory,perawatan alat berat dan prinsip FIFO 


\section{Pendahuluan}

Salah satu aktivitas penunjang dari sistem logistik adalah penyimpanan barang. Fungsi penyimpanan adalah untuk memaksimalkan penggunaan sumbersumber yang ada pada gudang dalam memenuhi kebutuhan pemakai dalam hal ini mekanik, divisi perawatan,produksi maupun pihak yang membutuhkan barang atau suku cadang.

PT. "X" merupakan suatu perusahaan yang bergerak di bidang tambang batu bara.Perusahaan ini mengelola sendiri lahannya mulai dari tahap exploration, exploitation, preparation \&shipment yaitu tahapan proses produksi batu bara dan juga sistem logistiknya. Pada bagian gudangPT. "X" terdapat permasalahan yang mengganggu pengelolaan dan berpengaruh pada bagian produksi. Permasalahan yang terjadi adalah terjadinya selisih stock barang antara jumlah stock yang ada pada data gudangdengan jumlah stock yang ada di dalam gudang. Efek yang diakibatkan dari terjadinya selisih jumlah stock adalah terjadinyakekosongan stock pada saat adanya permintaan barang dari konsumen, karena jumlah stock barang yang tidak terkontrol dengan baik

Tabel 1.1 Hasil Stock Opname Audit

\begin{tabular}{|l|r|r|}
\hline \multicolumn{1}{|c|}{ Deskripsi } & Item Suku cadang & Prosentase \\
\hline Item Suku cadang yang tidak bermasalah & 11764 & $93.3 \%$ \\
\hline Item Suku cadang yang terijadi selisih Stok & 847 & $6.7 \%$ \\
\hline llımlah Itrem sıkıı cadano & 17611 & $1 \mathrm{mm \%}$ \\
\hline
\end{tabular}

Dari table 1.1 diatas, ada $6.7 \%$ item suku cadangyakni sejumlah 847 item suku cadangyang mengalami selisih stock dari jumlah item suku cadang yang ada pada gudangPT. " $\mathrm{X}$ " yakni sejumlah 12.611 item. Hal ini tentunya akan menjadi kendala bagi kegiatan inventory suku cadangdigudangtersebut.

Berlatar belakang hal tersebut, maka dapat diperoleh rumusan masalah yaitu: 1. Apakahfaktor-faktorpenyebab terjadinya selisih jumlah stok suku cadang yang terdata dengan yang tersedia di gudangPT. "X"?

2. Apakah permasalahan pada gudang PT. "X" dan usahaapayang perlu dilakukan untuk mengatasi permasalahantersebut?

\section{Metode Penelitian}

\subsection{Jenis Penelitian}

Penelitianlapangan dengan metode observasi, dokumentasi dan wawancara dilakukan di PT."X"dilaksanakan tanggal 5 Januari sampai 8Maret 2016.

\subsection{Teknik Pengumpulan Data}

Dalam pengumpulkan data, ada beberapa teknik yang diterapkan oleh penulis, meliputi observasi, dokumentasi dan wawancarakepada supervisor, foreman dankaryawan / staff gudangyang dilakukan pada proses Receiving, Stock In, Invetory, Stock Opname, Stock Out, Administrationdan SOP gudang.

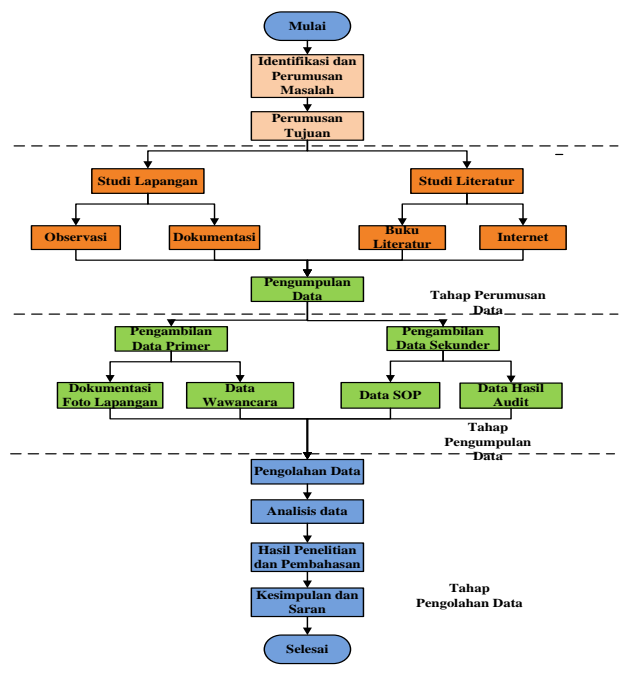

Gambar 2.1 : Diagram Alir Penelitian

Tabel 2.1 Metode Pengumpulan Data

\begin{tabular}{|c|c|c|c|}
\hline $\begin{array}{c}\text { Kelompok } \\
\text { Data }\end{array}$ & Data & Jenis Data & $\begin{array}{l}\text { Metode / } \\
\text { Sumber }\end{array}$ \\
\hline \multirow[t]{2}{*}{ Kuantitatif } & $\begin{array}{l}\text { Data Suku } \\
\text { cadang }\end{array}$ & Sekunder & $\begin{array}{l}\text { Head } \\
\text { Logistic }\end{array}$ \\
\hline & $\begin{array}{l}\text { Data Selisih } \\
\text { suku cadang }\end{array}$ & Sekunder & $\begin{array}{l}\text { Laporan } \\
\text { Hasil Audit } \\
\text { dan Stock } \\
\text { Opname } \\
\text { Akhir Tahun } \\
2015\end{array}$ \\
\hline
\end{tabular}




\begin{tabular}{|l|l|l|l|}
\hline Kualitatif & $\begin{array}{l}\text { Kondisi } \\
\text { pengelolaan } \\
\text { pergudanga } \\
\text { n yang ada } \\
\text { di gudang } \\
\text { tersebut }\end{array}$ & Primer & Observasi \\
\cline { 2 - 4 } & $\begin{array}{l}\text { Penyebab } \\
\text { dari kendala } \\
\text { yang terjadi } \\
\text { pada } \\
\text { gudangterse } \\
\text { but }\end{array}$ & Primer & -Observasi \\
& & & \\
& & \\
\end{tabular}

\subsection{Pengolahan dan Analisis Data}

Data yang terkumpul diolah dengan membuat tabulasi kemudian data tersebut dianalisis secara deskriptif.

\section{Hasil dan Pembahasan}

Hal yang menyebabkan terjadinya selisih jumlah stock suku cadangyang bertotal 847 item adalah barang atau suku cadangyangkeluar dari gudangtidak dibuatkan FPB (Form Pengeluaran Barang) terjadi pada 33 item suku cadang, suku cadang memiliki bentuk fisik yang sama dengan suku cadanglainsehingga salah dalam melakukan pemotongan jumlah stock terjadi pada 35 item suku cadang, 119 item suku cadanglainnya mengalami selisih karena hasil adjusment audit pada tahun 2013 yang tidak benar, dan sisanya yakni 660 item suku cadang yang terjadi selisih belum diketahui penyebabnya. Presentase penyebab terjadinya selisih suku cadangtersebut dapat dilihat pada tabel 3.1.di bawah ini.

Tabel 3.1 Penyebab Terjadinya Selisih Suku cadang

\begin{tabular}{|l|c|c|}
\hline \multicolumn{1}{|c|}{ Deskripsi } & $\begin{array}{c}\text { Item Suku } \\
\text { Cadang }\end{array}$ & Prosentase \\
\hline $\begin{array}{l}\text { Pengeluaran } \\
\text { tanpa FPB }\end{array}$ & 33 & $4 \%$ \\
\hline $\begin{array}{l}\text { Salah } \\
\text { Pemotongan }\end{array}$ & 35 & $4 \%$ \\
\hline $\begin{array}{l}\text { Hasil } \\
\begin{array}{l}\text { Adjustment } \\
\text { Audit }\end{array}\end{array}$ & 119 & $14 \%$ \\
\hline Belum diketahui & 660 & $78 \%$ \\
\hline \multicolumn{1}{|c|}{ Jumlah } & 847 & $100 \%$ \\
\hline
\end{tabular}

Selanjutnya permasalahan yang terjadi pada gudang alat berat PT. "X" dijelaskan di bawah ini.

\subsection{Aktivitas Penerimaan}

\section{1a. Permasalahan Pada Aktivitas Penerimaan}

Pihak User dalam hal ini seorang Supervisor atau foreman dari divisi maintenance atau produksi akan mengecek langsung Suku cadangtersebut berdasarkan kualitasnya (Quality Check) dan juga mengecek kesesuaian suku cadangtersebut sesuai dengan permintaan user tersebut dan terakhir user melakukan pengecekan jumlah suku cadang(Quantity Check). Pengecekan yang biasa dilakukan pada gudangPT."X" adalah denganmenggunakan sampel. Namun, karena proses pengecekan terkadang menggunakan sampling method maka terjadilah permasalahan yaitu pemasukan suku cadang yang tidak sesuai permintaan.

\section{1b.Perbaikan Pada Aktivitas Penerimaan}

Adapun usaha perbaikan yang penulis lakukan untuk meningkatkan performa pada proses penerimaan dan untuk mengatasi permasalahan tersebut adalah dengan melakukan proses pemeriksaan $100 \%$ Inspection kepada seluruh suku cadang yang dating baik secara quantity dan quality. Dengan menggunakan melakukan metode tersebut terbukti dapat menekan angka terjadinya kesalahan pemasukan suku cadang yakni suku cadang yang masuk tidak sesuai permintaan. Setiap suku cadangakan dicek satu persatu sesuai surat jalan ataupun dokumen good receiptsuku cadang tersebut. Adapun hasil dari penerapan cara tersebut adalah tidak terulang kembali kejadian seperti yang ditunjukkan pada tabel 3.1 pada gambar nomor 1 karena setiap suku cadang yang tidak sesuai akan langsung dibuatkan claim report. Dokumen claim report beserta suku cadang yang telah dikemas kemudian dikembalikan (reverse logistic) karena tidak sesuai dengan permintaan. 


\subsection{Aktivitas Penyimpanan}

\section{2aPermasalahan Pada Aktivitas Penyimpanan}

Kendala yang terjadi pada aktivitas penyimpanan pada proses find location and put the part yaitu adanya kondisi penyimpanan/peletakkan barang yang tidak tepat dan tidak rapi karena akan timbul masalah saat akan menggunakan prinsip FIFO (First In - First Out). Hal ini tentu berdampak kerugian kepada perusahaan, barang yang pertama masuk tidak dikeluarkan akan terus disimpan di gudang. Suku cadangtersebut akan mengalami kedaluwarsa atau korosif yang dapat merusak suku cadang.

\section{2b Perbaikan Pada Aktivitas Penyimpanan}

Penyimpanan suku cadang yang tidak sesuai dapat berpengaruh terhadap kualitas suku cadang tersebut. Oleh karenanya penulis melakukan usaha perbaikan yakni dengan mendesain rak dan mengimplementasikannya pada gudangPT."X".Penyimpanan ban ditempatkan diatas rack khusus, posisi ban vertikal (tidak ditidurkan/ditumpuk, dan disimpan didalam ruangan sehingga tidak terkena matahari secara langsung. Kemudiandiberi nomor urut yang dilakukan penulis. Pemberian nomor urut berdasarkan urutan masuknya ban tersebut ditujukan agar proses FIFO dapat berjalan dengan baik. Urutan pengeluaran ban akan berurutan sesuai nomor urut masuknya. Ban disimpan dan ditata rapi di rak dan tidak menghalangi jalan.Disamping itu penulis membuat box untuk menempatkan suku cadangyang berhamburan dan menempatkannya pada box yang telah dibuat dan diberikan daftar suku cadang yang dapat mempermudah storeman pada saat mencari suku cadang.Box tersebut digunakan untuk suku cadangyang berukuran kecil dan jumlahnya tidak banyak.

\subsection{Aktivitas Pengeluaran}

\section{3a Permasalahan Pada Aktivitas Pengeluaran}

Permasalahan pada aktivitas pengeluaran adalah terjadinya pengeluaran suku cadangtanpa adanya BPB(Bon Pengeluaran Barang) sehingga tidak ada proses pemotongan jumlah stok suku cadang pada data gudang. Hal tersebut terjadi akibat adanya user yang melakukan permintaan barang tanpa adanya FPB(Form Permintaan Barang) dengan alasan meminjam dahulu suku cadanguntuk dicoba terlebih dahulu. Namun, user tidak kembali untuk memberikan FPB. Selain itu hal yang samaterjadi saat akan overshift siang dengan malam, karena saling tidak adanya koordinasi satu sama lain jadi tidak ada yang meminta FPB ke user sampai hal tersebut terlupakan. Ada pula kendala akibat kesalahan penulisan namasuku cadang pada FPB yang ditulis oleh storeman karena suku cadangtersebut memiliki bentuk fisik yang sama dengan yang lainnya. Hal-hal tersebutlah yang mengakibatkan terjadinya selisih jumlah suku cadang antara data gudang dengan kondisi fisik.

\section{3b Perbaikan Pada Aktivitas} Pengeluaran

Untuk mencegah terulangnya kembali kejadian selisih jumlah suku cadang maka penulis melakukan usaha perbaikan yaitu dengan membuatkan stock card untuk masing-masing suku cadang yang disimpan. Fungsinya sebagai data manual dari jumlah masing-masing suku cadang dan memastikan semua proses pemasukan maupun pengeluran suku cadangakan tercatat untuk meminimalisir bahkan dapat menghilangkan terjadinya kesalahan ambilsuku cadang maupun terjadi selisih jumlah suku cadang.

\subsection{Aktivitas Pengontrolan}

\section{4aPermasalahan Pada Aktivitas Pengotrolan}

Aktivitas pengontrolan disebut juga dengan stock opname atau stock taking 
yaitu suatu aktivitas gudang yang dilakukan untuk mencocokkan jumlah suku cadang yang ada di data gudang dengan jumlah fisik suku cadang yang ada di gudangtersebut.Permasalahan yang ada di bagian pengontrolan adalah tidak adanya perencanaan atau penjadwalan secara baik oleh bagian pengontrolan. Sebagai contoh permasalahan yang timbul adalah terjadinya selisih jumlah suku cadangsesuai hasil dari audit akhir tahun 2014. Ini adalah indikasi bahwa aktivitas pengontrolan tidak berjalan dengan baik karena tidak adanya penjadwalan pengontrolan oleh pihak internal gudangtesebut.

\section{4b Perbaikan Pada Aktivitas Pengontrolan}

Usaha perbaikan yang penulis lakukan yakni melakukan pengontrolan dan trackinginventory untukstock opname sekaligus melakukan tracking pada suku cadang yang mengalami selisih jumlah suku cadang.Hasil dari proses tracking yang penulis dan team lakukan adalah ditemukannya beberapa penyebab terjadinya selisih suku cadangyang terjadi dari 660item suku cadangselisih yang belum diketahui penyebabnya yang dapat dilihat pada tabel dibawah ini.

Tabel 3.3 Hasil Tracking SelisihSuku Cadang

\begin{tabular}{|l|c|c|}
\hline \multicolumn{1}{|c|}{ Deskripsi } & $\begin{array}{c}\text { Item Suku } \\
\text { Cadang }\end{array}$ & Prosentase \\
\hline $\begin{array}{l}\text { Barang Pindah ke } \\
\text { Gudang Baru }\end{array}$ & 198 & $30 \%$ \\
\hline $\begin{array}{l}\text { Pengeluaran tanpa } \\
\text { FPB }\end{array}$ & 13 & $2 \%$ \\
\hline Salah Pemotongan & 7 & $1 \%$ \\
\hline $\begin{array}{l}\text { Dilakukan } \\
\text { Pengadjustan }\end{array}$ & 442 & $67 \%$ \\
\hline \multicolumn{1}{|c|}{ Jumlah } & 660 & $100 \%$ \\
\hline
\end{tabular}

Pada tabel di atas terlihat bahwa dari 660item suku cadang yang sebelumnya belum diketahui penyebab terjadi selisihnya adalah terjadi karena adanya pemindahan barang kegudang yang baru tanpa adanya pemindahan lokasi pada data gudang adalah sejumlah 198item, pengeluaran barang tanpa FPB sejumlah 13, terjadi 7 kasus kesalahan pemotongan dan 442 sisa item lainnya dilakukan pengkalibrasian ulang untuk menormalkan kembali jumlah suku cadang yang selisih pada data gudang. Selanjutnya apabila direkapitulasi dari hasil sebelumnya, maka penyebab terjadinya selisih suku cadang sebanyak 847item adalah seperti yang ditunjukkan pada tabel3.4.

Tabel 3.4. Penyebab Selisih Stok Suku Cadang

\begin{tabular}{|l|c|c|}
\hline \multicolumn{1}{|c|}{ Deskripsi } & $\begin{array}{c}\text { Item Suku } \\
\text { Cadang }\end{array}$ & $\begin{array}{c}\text { Prosentas } \\
\text { e }\end{array}$ \\
\hline $\begin{array}{l}\text { Barang Pindah ke } \\
\text { Gudang Baru }\end{array}$ & 198 & $23 \%$ \\
\hline $\begin{array}{l}\text { Pengeluaran tanpa } \\
\text { FPB }\end{array}$ & 46 & $5 \%$ \\
\hline Salah Pemotongan & 42 & $5 \%$ \\
\hline $\begin{array}{l}\text { Dilakukan } \\
\text { Pengadjustan }\end{array}$ & 442 & $52 \%$ \\
\hline $\begin{array}{l}\text { Hasil Adjustment } \\
\text { Audit }\end{array}$ & 119 & $14 \%$ \\
\hline \multicolumn{1}{|c|}{ Jumlah } & 847 & $100 \%$ \\
\hline
\end{tabular}

\section{Kesimpulan}

Dari hasil analisis data yang sudah dilakukan dapat disimpulkan:

1. Faktor-faktorpenyebab terjadinya selisih jumlah stok suku cadang yang terdata dengan yang tersedia di gudang PT. "X" adalah barang pindah ke gudang baru 198 item (23\%), pengeluaran tanpa FPB 46 item (5\%), Salah pemotongan stok 42 item $(5 \%)$, dilakukan pengadjustan 442 item $(52 \%)$ dan hasil adjustment audit 119 item (14\%).

2. Permasalahan pada gudang PT. " $X$ " dan usaha apa yang perlu dilakukan untuk mengatasinya yaitu:

a.Petugas tidak teliti saat proses pengecekan suku cadang dan terkadang masih menggunakan metode sampling dalam pengecekan suku cadang. Usaha perbaikannya adalah melakukan pengecekan suku cadang masuk dengan metode $100 \%$ inspection. 
b.Kegiatan penyimpanan suku cadang yang dilaksanakan masih kurang baik. Usaha perbaikannya adalah menempatkan suku cadang atau barang secara tepat dan rapi dengan prinsip FIFO.

c. Adanya suku cadang yang dapat keluar tanpa adanya FPB dan pemotongan jumlah suku cadang. Usaha perbaikannya adalah dengan menyimpan suku cadang pada masingmasing rak dan pembuatan stock card untuk mengontrol barang keluar.

d.Aktivitas pengontrolan tidak dilaksanakan dengan baik. Usaha perbaikannya adalah melakukan tracking pada item suku cadang yang terjadi selisih untuk didata ulang keberadaannya.

\section{Ucapan Terimakasih}

Terimakasih ditujukan kepada manajer PT."X" yang telah menyediakan tempat untuk penelitian ini.

\section{Daftar Pustaka}

Burgess, R.G. 1984. In the Field: An Introduction to Field Research. London: George \& Unwin.

David, Fred R., 2011. Manajemen Strategis. Jakarta: Salemba Empat.

Garg H. P. 1976. Industrial Maintenance, S.Chand and Company Ltd, New Delhi.
Higgin, Lindley. R. 1995, Maintenance Engineering Hand Book 5th Ed,Mc Graw Hill, Inc, New York.

John Warman. 2004. Manajemen Pergudangan. Pustaka Sinar Harapan.Jakarta

Modern School Shop Planning 7th Ed. 1978. Prakken Publication, Inc, Michigan.

Neal Michael, J. 1999, The Tribology Hand Book 2nd Ed, Butter Worth Heinemann, Oxford.

P. Gopalakrishnan and A.K. 2004. Banerji. Maintenance and Spare Parts Management. Prentice Hall of India, New Delhi

Ricky Martono. 2013. Practical Inventory Management : Menciptakan Keunggulan Operasional Melalui Sediaan. PPM Manajemen. Jakarta.

Sekaran, U. 2006. Metodologi Penelitian untuk Bisnis. Jakarta: Salemba Empat.

Standard Operational Procedure: Logistic (Procurement, Inventory\& Fuel)PT."X" Periode 2013.

Sumayang, L. 2003. Dasar-Dasar Manajemen Produksi dan Operasi. Jakarta: Salemba Empat 